\title{
FORMAS ELEMENTARES DA VIDA ALIENÍGENA: SAGRADO \& PROFANO EM DUNA (1965) DE FRANK HERBERT
}

\author{
Elementary Forms of Alien Life: Sacred and Profane in Dune (1965) by Frank Herbert
}

\author{
BUSCH, Willian Perpétuo ${ }^{1}$ \\ UFPR - Paraná/Brasil
}

\begin{abstract}
RESUMO: O objetivo deste artigo é construir uma análise sociológica da obra de Duna (1965) de Frank Herbert. Tratado como um dos principais textos da Ficção Científica, Duna produz uma narrativa que faz uso de elementos religiosos. Estes, uma vez postos sobre o escrutínio das teses sociológicas de Émile Durkheim, Marcel Mauss, Henri Hubert e Max Weber, revelaram seus mecanismos de funcionamento. A partir de Durkheim, percebemos como a religião no texto foi construída a partir da oposição entre sagrado e profano e é na oscilação de um para o outro que os personagens operam. Visando compreender isso, as proposições de Mauss e Hubert nos forneceram um arsenal para compreender como um objeto pode oscilar entre os dois campos (sagrado e profano). Em específico, percebemos como Paul Atreides vai sendo dotado de sacralidade na medida que consolida sua posição dentro de dois conjuntos de pensamento distintos. Por fim, com as reflexões de Weber compreendemos que essa sacralidade adquirida por Paul foi possível a partir de um regime ascético que viabiliza sua ascensão como um messias.
\end{abstract}

Palavras-chave: História da Ficção Científica; Sociologia da Ficção Científica; Duna; Sociologia da Religião

ABSTRACT: The aim of this article is to make a sociological analysis of Frank Herbert's Dune (1965) work. Treated as one of the greatest science fiction texts, Dune produces a narrative that makes use of religious elements. These, once put on the scrutiny of the sociological theses of Durkheim, Marcel Mauss, Henri Hubert and Max Weber, revealed their working mechanisms. From Durkheim we realize that religion operates between sacred and the profane. These reflections goes side by side with the propositions of Mauss and Hubert in providing the arsenal for such an object between the two fields (sacred and profane). In specific, we realize how Paul Atreides will be endowed with sacredness as he consolidates his position into two sets of distinct thoughts (macro-galactica and micro-planetary). Finally, with Weber's reflections understanding how that sacredness was acquired by Paul, it enable him to use ascetic regime that paves way to his ascension as a messiah and emperor.

Keywords: History of Science Fiction; Sociology of Science Fiction; Dune; Sociology of Religion..

1 Mestre em Antropologia pela Universidade Federal do Paraná. Bacharel em Filosofia e Licenciado em Filosofia pela Universidade Federal do Paraná. E-mail: busch.wpb@gmail.com

REVISTA RELEGENS THRÉSKEIA - 2018 - UFPR - UEPA 


\section{Introdução}

A década de 1960 marcou um momento de transição para a Ficção Científica. As revistas, principal meio de veiculação e divulgação dessa literatura começaram a perder a força. Os motivos para isso são vários. Um dos principais foi a substituição dos números com histórias de diferentes autores por livros no formato de brochuras que passaram a ser vendidos pelo mesmo preço. Além dessa transição material, houve também outra de cunho temático: a Ficção Científica se distanciava cada vez mais do modelo das ciências mecânicas e flertava com as ciências sociais. Duna ${ }^{2}$ (1965), de Frank Herbert (1920-1986), é uma obra exemplar para marcar essa transição material e temática. O objetivo deste artigo almejou compreender o principal elemento da narrativa de Duna, a saber, a questão da religião, em vista da construção e operação das categorias de sagrado e profano (Durkheim, Mauss e Hubert), bem como do processo de construção do profeta carismático (Weber).

A primeira versão de Duna apareceu serializada pela Analog Science Fact $\rightarrow$ Science Fiction em três números, de dezembro de 1963 e fevereiro de $1964^{3}$. Na ocasião, a Analog era editada por John W. Campbell, a principal referência do período e que havia sido a peça chave para a emergência de outros autores que já eram amplamente conhecidos na época: Robert Heinlein, Isaac Asimov, E. E. "Doc" Smith, entre outros. Herbert havia publicado alguns textos antes, como Looking for Something ${ }^{4}$

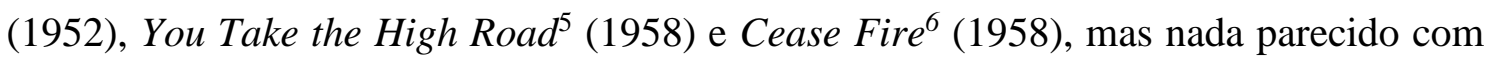
o patamar que Duna viria a alcançar.

Em 1965, após ser recusado por dezenas de editoras, Herbert conseguiu publicar aquela serialização da Analog na forma de um livro ${ }^{7}$. Curiosamente, a editora que aceitou a empreitada foi a Chilton, que não estava inserida no mercado de literatura mas sim na produção de manuais para motocicletas. Essa primeira edição continha capa de John Schoenherr, uma arte impressionante que marcava a identidade visual da narrativa com tons pastéis e que depois foram expandidas para versões ilustradas. Nesse mesmo

2HERBERT, Frank, Dune, New York: Chilton Books, 1965.

3HERBERT, Frank, Dune World (Part 1 of 3), Analog Science Fiction - Science Fact, v. LXXII, n. 4, p. 17-48, 1963; HERBERT, Frank, Dune World (Part 2 of 3), Analog Science Fiction - Science Fact, v. LXXII, n. 5, p. 48-85, 1964; HERBERT, Frank, Dune World (Part 3 of 3), Analog Science Fiction - Science Fact, v. LXXII, n. 6, p. 40-71, 1964. 4HERBERT, Frank, Looking for Something?, Startling Stories, v. 25, n. 3, p. 124-140, 1952. 5HERBERT, Frank, You Take the High Road, Astounding Science-Fiction, v. 61, n. 3, p. 97-108, 1958. 6HERBERT, Frank, Cease Fire, Astounding Science-Fiction, v. 60, n. 5, p. 51-68, 1958. 7HERBERT, Dune. 
ano, foi resenhada por Judith Merril ${ }^{8}$ para a The Magazine of Fantasy and Science Fiction, bem como por P. Schuyler Miller ${ }^{9}$ na Analog Science Fiction - Science Fact, e por Algis Budrys ${ }^{10}$ na Galaxy.

A existência destas resenhas nas principais revistas de Ficção Científica da época revela que o campo foi sensível à publicação de Herbert e se interessou por ele. Mas Dune foi além, recebendo os principais prémios da área: Hugo Award (1966); Nebula Award (1966) e Locus Award (1975). Republicada constantemente, a obra se tornou o ponto de partida para a criação de um vasto universo que além de literário, influenciou grupos musicais, foi adaptada para o cinema e para os quadrinhos.

Em 1969, Herbert lançou Dune Messiah ${ }^{11}$, a continuação da narrativa que se passa anos depois do fim dos eventos do primeiro livro. O terceiro livro, Children of Dune ${ }^{12}$, foi publicado em 1976, sendo seguido por God Emperor of Dune ${ }^{13}$ (1981), Heretics of Dune ${ }^{14}$ (1984), e Chapterhouse: Dune $e^{15}$ (1985). Junto com os novos títulos, aqueles que já haviam sido lançados eram constantemente traduzidos para línguas estrangeiras, e também reimpressos no inglês. Após a morte de Herbert em 1986, seu filho Brian Herbert (1947-) e Kevin J. Anderson (1962-), vêm lançando narrativas a partir dos esboços e anotações deixadas pelo autor.

No cinema, a primeira tentativa de adaptar Dune foi proposta por Alejandro Jodorowsky, em 1973-1974. O diretor não encontrou ninguém disposto a financiar seu trabalho, que possuía um roteiro amplo e almejava uma película com duração de quatorze horas. Em 2013, um documentário dirigido por Frank Pavich foi lançado retratando parte do processo de produção de Jodorowsky. Em 1984, Duna chegou aos cinemas a partir da direção de David Lynch e edição de Dino de Laurentiis. Frank Herbert participou de parte das filmagens, mas o filme não teve sucesso imediato. Problemas entre Lynch e a equipe de edição fizeram com que o diretor solicitasse que seu nome fosse retirado dos créditos finais. Mas, com o passar do tempo, o filme se tornou um clássico e ganhou novas edições - entre elas, uma versão estendida com

8MERRIL, Judith, Review: Dune by Frank Herbert, The Magazine of Fantasy and Science Fiction, v. 30, n. 3, p. 51, 1966.

9MILLER, P. Schuyler, Review: Dune by Frank Herbert, Analog Science Fiction - Science Fact, v. LXXVII, n. 2 , p. 140, 1966.

10BUDRYS, Algis, Review: Dune by Frank Herbert, Galaxy, v. 24, n. 4, p. 67-70, 1966.

11HERBERT, Frank, Dune Messiah, New York: G. P. Putnam's Sons, 1969.

12HERBERT, Frank, Children of Dune, New York: Berkley Medallion Books, 1976.

13HERBERT, Frank, God Emperor of Dune, New York: New English Library, 1981.

14HERBERT, Frank, Heretics of Dune, New York: New English Library, 1984.

15HERBERT, Frank, Chapterhouse: Dune, New York: New English Library, 1985.

REVISTA RELEgENS THRÉSKEIA - 2018 - UFPR - UEPA 
várias cenas que foram removidas e uma versão feita por um fã ${ }^{16}$ que almejou ser o mais fiel possível ao texto de Herbert e ao roteiro de Lynch. Em 2000, a emissora SyFy lançou uma minissérie com o título de Frank Herbert's Dune, dividida em três episódios. Produzida por Richard P. Rubinstein e Vittorio Storaro, roteiro e direção de John Harrison. Diferente da versão de 1984, essa foi bem recebida pelo público e pela crítica, sendo indicada ao Emmy Award e premiada na categoria de cinematografia e de efeitos especiais. Em 2003, uma continuação baseada em Dune Messiah ${ }^{17}$ e Children of Dune $^{18}$ foi lançada pela SyFy, com direção de Greg Yaitanes.

Neste artigo, nosso objetivo será trabalhar apenas com Duna, mas futuramente expandiremos nossas reflexões para as outras obras da franquia. A primeira tradução da obra para o português europeu foi feita por Eurico da Fonseca, publicado em 1985 pela Livros do Brasil. A segunda tradução (agora para o português brasileiro) foi lançada em 2010 pela Editora Aleph, sendo feita por Maria do Carmo Zanini. Para a realização de nossa discussão, tomamos por base a edição de 1965 de Frank Herbert e as citações retiradas do texto de Zanini (a partir da nova edição de 2017).

A estrutura da obra é a seguinte: livro primeiro - Duna; livro segundo Muad'Dib; livro terceiro - O Profeta. Dentro desses, há capítulos não numerados que são abertos com citações. Tais citações são de livros ficcionais que teriam sido escritos depois de Duna e que oferecem insights sobre a narrativa. Há também três apêndices: $I$. A ecologia de Duna; II. A religião de Duna; III. Relatório acerca dos motivos e propósitos das Bene Gesserit. Como sugere o título, o primeiro apêndice apresenta o sistema ecológico de Duna a partir do ponto de vista de um planetólogo que terá importância na história. Já o segundo apêndice é uma historicização das práticas religiosas dos Fremen. Como a história se passa em um futuro distante, Herbert configura uma religião que combina aspectos do Budismo Zen, Islã e Cristianismo. O terceiro apêndice situa alguns aspectos da ordem das Bene Gesserit e sua teologia, amarrando um outro aspecto da religião que não havia sido tocado no apêndice anterior. Por fim, Herbert também inseriu um dicionário com algumas palavras-chave e seu significado.

\section{Desenvolvimento}

16Disponível em: https://archive.org/details/Dune1984AlternativeEditionReduxfanedit 17HERBERT, Dune Messiah. 18HERBERT, Children of Dune. 
A questão feita por nós a Dune é o seguinte - como pode ser possível pensar seu texto a partir de uma perspectiva sociológica?

Nossa sugestão é que, a partir do foco na trajetória de um indivíduo, Paul Atreides, é possível tratá-lo como inscrito dentro de um conjunto de fenómenos de cunho religioso. Para Émile Durkheim, em The Elementary Forms of Religious Life19, a religião é social, e suas representações são coletivas e expressam uma realidade que também é coletiva. Os ritos que são executados dentro de uma religião visam ativar, manter ou recriar certos estados mentais que dizem respeito as crenças. No mais, as categorias pelas quais os sujeitos dividem o mundo tem sua origem na religião, portanto são sociais e frutos do pensamento coletivo20. Assim, "é a própria autoridade da sociedade, transferindo-se para certas maneiras de pensamento que são indispensáveis para toda a ação comum"21 E, em Dune, conflui no que chamaremos da produção da sacralidade de Paul, processo que se manifesta na forma de um carisma.

Em outras palavras, nossa proposta é tratar o texto como marcado por diferentes processos rituais religiosos, nos quais a sacralidade de Paul é construída, e permite sua emergência como uma figura profética, que exerce o controle da religião (e da política), a partir de seu carisma. Para delimitar, e interpretar os rituais identificados, nossa proposta foi combinar as teorias de Durkheim com àquelas de Marcel Mauss e Henri Hubert22. A teoria do sacrifício, tal como foi proposta por estes dois autores, permitiu compreender que a sacralidade experimentada por Paul foi se agrupando na foram de um carisma, e que esse ganha forma a partir de um tipo de treinamento e disciplina individual que antecede o personagem. Para compreender esse movimento, fizemos uso da proposta teórica de Max Weber23, em torno da emergência do profeta dentro de um cenário social.

Tradicionalmente, Weber e Durkheim são tratados como autores que tem propostas interpretativas opostas. O primeiro teria focado sua análise no impacto do indivíduo sobre a coletividade, enquanto o segundo feito o oposto, de modo que é a

19DURKHEIM, Emile, The Elementary Forms of Religious Life, London \& New York: George Allen \& Unwin, Ltd. \& The Macmillan Company, 1915.

20Ibid., p. 07,09,14,17.

21 No original: "It is the very authority of the society, transfering itself to a certain manner of thought which is the indispensable condition of all common action.” Tradução nossa. Ibid., p. 17.

22MAUSS, Marcel; HUBERT, Henri, Sacrifice: Its Nature and Its Function, Chicago: University of Chicago Press, 1964.

23WEBER, Max, Economy and Society - An Outline of Interpretive Sociology. Volume 1 \& 2., Berkeley, Los Angeles, London: University of California Press, 1968.

REVISTA RELEGENS THRÉSKEIA - 2018 - UFPR - UEPA 
coletividade que controlaria integralmente o indivíduo. Essa oposição, que é reificada em manuais, e leituras atravessadas de ambos os autores, não nos parece ter muito sentido. Durkheim é um autor que nos permite compreender como o ritual é estabelecido, e qual sua dinâmica de funcionamento, bem como sua importância constitutiva do próprio social. Já Weber, apesar de ter um peso menor em nosso trabalho, nos permite a elucidação da dinâmica do indivíduo dentro da sociedade, na medida em que este faz adaptações, insere-se no coletivo, e passa a agir sobre ele. A heresia cometida aqui, portanto, é teoricamente útil para tratar de Duna a partir de uma perspectiva social.

A questão da sacralidade de Paul não é dada de maneira imediata na narrativa. $\mathrm{O}$ que ocorre é uma construção a partir da inscrição do personagem dentro de diferentes grupos sociais, sendo afetado e reagindo a estes. O sucesso destas aproximações, que produzem constantes tensões (se não fosse o caso, não haveria necessidade de nenhum ritual), revelam as formas da sociedade retratada. Convém lembrar que, para Max Weber, o carisma está ligado com poderes oriundos da esfera religiosa, sendo divididos em dois tipos. O primeiro é um carisma dado de antemão para o sujeito (não precisa ser construído), enquanto o segundo é construído progressivamente a partir de regimes ascéticos e disciplinares24. É esse segundo tipo de carisma, produzido socialmente, que nos interessa.

Nosso primeiro passo, portanto, foi identificar quais são as formas rituais às quais Paul participou. Isso tornou possível perceber que a sacralidade opera em termos do modelo do rito do sacrifício, como proposto por Mauss e Hubert25. O sacrifício, para estes autores, é um ato religioso que, ao ser executado, implica em uma modificação em torno da pessoa, ou do objeto, que participa dele26. Paul irá ocupar a posição de sacrificante, na medida em que os rituais que ele participa são de cunho de iniciação. Para Mauss e Hubert, nos ritos de iniciação, o sacrificante precisa retornar para o mundo profano mantendo algum tipo de sacralidade que foi adquirida pelo processo. E, o que percebemos em Duna, é o acumulo sistemático de tal sacralidade.

O primeiro movimento para a sacralização de Paul é sua filiação, tanto em termos paternos quanto maternos. Seu pai era Duque Leto Atreides, regente da casa 
Atreides. Em Duna, há diversas casas reais que se organizam em torno de uma liga, conhecida como Landsraad. Estas, em teoria, seriam chefiadas pelo Padishah Emperor (doravante, Imperador), que é membro da casa Corino. Esse modelo de cunho feudalespacial é constantemente tencionado pelo fato de que as casas que integram o Landsraad têm relações conflituosas, como os Atreides e os Harkonnen. Todavia, as casas também fazem oposição ao Imperador e impedem que este favoreça uma casa em prol da outra, uma vez que isso poderia resultar em instabilidades políticas. Há relações de parentesco entre o Imperador e os líderes das casas, de modo que a hereditariedade sanguínea perpassa isso.

Por parte de pai, portanto, Paul tinha o direito a liderança da casa Atreides. Por parte de mãe, Paul descende de Lady Jessica, concubina oficial de Leto e advinda da ordem das Bene Gesserit. A relação entre Leto e Jessica é tal que ela não ocupa a posição de esposa, o que possibilitaria uma futura aliança com outra casa a partir do casamento. No mais, é a partir das Bene Gesserit que Paul será identificado como o Kwisatz Haderach. Sobre a ordem, e sobre esta posição, discutiremos logo a frente.

Essa identificação ocorre a partir de um rito de iniciação experimentado por Paul, na forma do Gom Jabbar. Para além de sua descendência paterna, o Gom Jabbar é um procedimento sacrificial no qual um certo grau de sacralidade será conferido para Paul, na medida em que esse estabelece uma primeira diferenciação entre humanos e não-humanos (animais, máquinas). Isso é, os humanos (sagrado) são separados do mundo não-humano (profano) e, com o encerramento do rito, a sacerdotisa responsável por sua execução admitirá a possibilidade de Paul ser o Kwisatz Haderach, mas isso seria decidido a partir de outro rito. No mais, ela percebeu que Paul vem sendo treinado por sua mãe em várias técnicas de controle corporal e da respirações exclusivas das Bene Gesserit e autoriza que ele seja instruído, também, no controle da Voz27. Práticas ascéticas que corroboram para sua sacralização carismática.

Todavia, antes da análise dos rituais da narrativa, é necessário contextualizar seu desenvolvimento. A casa Atreides foi enviada, pelo Imperador, para assumir o controle do planeta de Arrakis. O Imperador fazia isso pois se sentia ameaçado pela crescente popularidade de Leto dentro do Landsraad. No mais, os rivais dos Atreides, a casa

27Voz, grafada com letra maíscula, diz respeito a uma técnica de controle das Bene Gesserit. Na medida em que a Bene Gesserit consegue identificar os padrões de fala, e comportamento, de um sujeito, ela pode controlar seus atos de modo imediato a partir do uso da Voz. 
Harkonnen, que outrora administrava Arrakis, realizou um acordo secreto com o Imperador para que este fizesse uso de sua tropa de elite, os Sardaukar, em um futuro ataque contra os Atreides. Tratava-se de um pacto secreto, pois se as casas do Landsraad percebessem que o Imperador estava isolando seus principais antagonistas e eliminando-os um a um, poderia vir a causar um estado de guerra civil. Dentro desse contexto de transição de capital, com os Atreides abandonando o planeta de Caladan e indo residir integralmente em Arrakis, percebemos que existe um problema de ordem social, que também é econômico e político.

Para Weber28, uma figura carismática, tal como sugerimos que Paul seja, aparece em situações nas quais há algum tipo de conflito. Isso é, dentro desses problemas de ordem, um profeta emerge para instituir mudanças na sociedade como um todo. A chegada da casa Atreides em Arrakis é análoga no sentido que, quando Leto iniciou seu governo, seu primeiro objeto foi instituir uma série de reformas sociais e políticas locais para garantir a aliança com os nativos e se reestruturar economicamente, uma vez que a mudança resultou em extensos gastos. Convém notar também que Leto não teria outra saída exceto aceitar a ordem do Imperador (que se fosse rejeitada implicaria em exílio). Para compreender a importância econômica do planeta de Arrakis, devemos ressaltar os principais aspectos de seu sistema ecológico, compostos pelo par água e especiaria.

Para os observadores do Império e ao visitante externo, Arrakis é um planeta desertificado em sua total extensão, não havendo nenhum tipo de fonte externa aquífero. Nas regiões mais rochosas, algumas cidades foram construídas, sobretudo para fins comerciais em torno da especiaria. A manutenção do planeta para a vivência de mamíferos é garantida pela troca entre nitrogênio e oxigênio feita pelos vermes do deserto, minhocas gigantes que habitam o subterrâneo do planeta e mantém o ecossistema estável. Por conta da predominância da paisagem desértica e da baixa taxa de umidade (que aumenta no período noturno), a água é o bem de consumo mais importante para qualquer sujeito que ali esteja.

Para além das cidades, ocultos nas montanhas e nas regiões do sul, consideradas como incapazes de sustentar qualquer forma de vida, a sociedade Fremen floresce. Habitantes do deserto, trata-se de uma cultura tribal organizada em torno da manutenção

28WEBER, Economy and Society - An Outline of Interpretive Sociology. Volume 1 \& 2., p. 440.

REVISTA RELEgENS THRÉSKEIA - 2018 - UFPR - UEPA 
da água. Sua vestimenta principal é o trajestilador, uma roupa especial que cobre o sujeito, garantindo que toda água seja re-captada, filtrada e reaproveitada. Herbert descreveu que "seu tecido é um microssanduíche com as funções de dissipar o calor e filtrar os dejetos do corpo29", de modo que a "a umidade reaproveitada torna-se disponível por meio de um tubo que vem de bolsas coletoras30".

Se há uma ontologia dentro de Duna, seu núcleo elementar é a água. Dentro da sociedade Fremen, há três conceitos principais sobre a água, que revelam sua sacralidade: fardo d’água, hidrofichas e hidrodisciplina.

No glossário de Duna, Herbert definiu o fardo d'água como "uma dívida de gratidão extrema31". Trata-se de um tipo de obrigação que pode vir a existir entre duas pessoas (Fremen) e pode ser traduzida como um "valor em água", que serve para indicar a importância e peso destas relações. Essa relação da água como um elemento de união aparece também quando duas pessoas (ou lideranças) selam pactos a partir do ato de cuspir no chão. Realizar tal ato seria ofensivo para o observador imperial, mas para os Fremen é visto como um ato de extremo respeito. Em Arrakis, derramar a água para outro estabelece uma relação de amizade e de pertencimento de um sujeito para com um grupo (ou entre dois grupos). O oposto desta prática é o ato de matar os inimigos para “tomar32” sua água.

A hidroficha é composta por anéis metálicos que servem para marcar a quantidade de água que aquele indivíduo possui. Não cabe ao sujeito carregar sua água, mas aos hidromestres, que têm tal função. Os hidromestres operam, portanto, como sacerdotes. As cidades Fremen são ocultas e chamadas de sietch, nas quais há depósitos de água em grandes reservatórios e apenas os hidromestres podem retirar qualquer quantidade dali. Por fim, a hidrodisciplina é esse conjunto de práticas sociais e culturais dos Fremen para o máximo aproveitamento da água, desde sua captação com aparelhos como os captadores de vento, e também o uso e manutenção dos trajestiladores.

Com segurança podemos afirmar que a água é sagrada para os Fremen, mas não é o único tipo de sagrado que existe. Sua sacralidade está na forma em que ela organiza, mantém, e reproduz a sociedade Fremen. Ela é sagrada na medida em que remete a um

29HERBERT, Frank, Duna, São Paulo: Aleph, 2017, p. 671.

30Ibid., p. 656.

31Ibid.

32Em inglês é "take" - aqui há um duplo sentido do "tomar" como um ato de posse, e o "tomar" como tomar uma bebida.

REVISTA RELEGENS THRÉSKEIA - 2018 - UFPR - UEPA 
tipo de sentimento coletivo de respeito, que Durkheim considerou como algo que não pode se misturar, de forma alguma, com o profano33. E, nem com outro tipo de sagrado - os vermes do deserto.

Além dos Fremen e sua sociedade, a presença humana no planeta de Arrakis é somada por sujeitos (citadinos, mas também mercenários) que estão envolvidos com o processo de extração e venda da especiaria. Dois pontos devem ser considerados - a função da especiaria e a relação dessa com o ecossistema de Arrakis.

A especiaria é a substância34 que sustenta toda a economia da galáxia. Trata-se de uma droga, sendo que seu efeito primordial serve para expandir a consciência de seu usuário, mas também é utilizado como uma especiaria gastronômica, bem como aumenta o tempo de vida daqueles que o consomem. O consumo da especiaria é aditivo e gera uma dependência cada vez maior. Não há tratamentos para sua dependência e a abstinência causa morte no sujeito. O único planeta que produz a especiaria é Arrakis e seus nativos se destacam por uma característica biológica: o consumo progressivo da especiaria e torna os olhos de seus usuários completamente azuis (retina, íris e pupila).

Para a ordem das Bene Gesserit, a especiaria é fundamental para seus principais rituais, como o de emergência das Reverendas Mães (os Fremen tem um rito análogo). Estas são dotadas da memória coletiva35 de todas as sacerdotisas que vieram a ocupar tal posição no passado e isso só é possível por conta da expansão de consciência fornecida pelo spice. A especiaria também é importante para a Guilda Espacial. A navegação galáctica em Duna, em termos de longa distância, só é possível por conta dos navegadores desta organização, que por conta do uso constante e excessivo do spice, tiveram uma evolução física e mental para além do compreensível e são capazes de dobrar o espaço-tempo, permitindo o deslocamento das naves espaciais.

Como mencionamos, o que torna Arrakis singular é que essa especiaria. $\mathrm{Na}$ primeira parte da narrativa de Herbert, a relação entre essa droga e os vermes do deserto não é estabelecida, sequer é compreendida pelo Império ou pelas Casas. Todavia, na medida em que Paul adentrou na sociedade Fremen, esse sistema é complexificado e explicitado. Há uma relação de dependência entre os vermes do deserto e a especiaria, na medida em que os vermes do deserto são: produtores, consumidores e protetores. É

33DURKHEIM, The Elementary Forms of Religious Life, p. 265-266.

34Res extensa que afeta e potencializa a res cogita.

35Também chamada de Other Memory.

REVISTA RELEgens thrésKeIA - 2018 - UFPR - UePA 
pelo último item que o processo de mineração da especiaria é constantemente ameaçado pelos vermes do deserto que são sensíveis e percebem qualquer tipo de vibração no solo. Sua capacidade de destruição das máquinas mineralizadoras é quase instantâneo. Em livros posteriores, Herbert tratou da biologia dos vermes do deserto com maior cuidado, mas isso foge da presente discussão.

Vimos, também, que a água é sagrada para os Fremen. O mesmo não pode ser dito sobre a especiaria. Trata-se de uma substância profana, tendo apenas valor alimentar. Os Fremen mineram a especiaria como uma forma de suborno para que a Guilda Espacial não coloque nenhum satélite no céu de Arrakis (e venha a descobrir sobre a real extensão dos Fremen). Por outro lado, os vermes do deserto são sagrados para os Fremen. Tal sacralidade atravessa o rito de iniciação à juventude - marcada pela experiência de cavalgar uma minhoca, bem como o rito da água da vida. Convém perceber que a sacralidade dos vermes do deserto não é igual, ou equivalente, à sacralidade da água. Estes dois tipos de sagrados - positivo e negativo - por assim dizer, não podem entrar em contacto.

Há dois motivos para a proibição do contato: o primeiro é que a água é uma substância tóxica para os vermes do deserto e pode causar sua morte. A segunda é que o rito da água da vida, na qual um criadorzinho (pequeno verme do deserto) é sacrificado e dele extraído um tipo de água que será purificada e terá uso ritual (rica em especiaria). Há um uso proibido: a água da morte, que se realizada viria a eliminar todos os vermes do deserto de Arrakis e, portanto, toda a especiaria.

A arma ritual Fremen é a adaga-crys, uma faca produzida a partir do dente de um verme do deserto. Ela não pode ser vista por ninguém que seja de fora do planeta, e se retirada de sua bainha, só pode ser guardada novamente após ter tido contacto com sangue. Trata-se de uma arma ritual, e deve ser mantida constantemente junto ao corpo de seu portador, pois caso isso não ocorra, ela irá se dissolver.

Os Fremen se referem aos vermes do deserto de, pelo menos, três formas: Criador, Criadorzinho e Shai-Hulud. As primeiras são os vermes do deserto, comumente cavalgadas pelos nativos. A segunda refere-se àquelas formas menores, utilizadas para 0 ritual da Água da Vida. A terceira não é apenas um verme do deserto, mas também a ideia de Deus (ou de divindade) dos Fremen. Para compreender isso, é necessário perceber que se tratam de um totem da tribo, no sentido dado por Durkheim ao termo. 
Para Durkheim, a crença religiosa, independente de qual seja, pressupõe a separação entre dois tipos de coisas - o sagrado e profano. Tudo que diz respeito ao pensamento sagrado está amarrado pelas crenças, lendas, mitos, dogmas, etc, que expressam e são a expressão da sociedade. Os ritos, portanto, são regras de conduta que devem ser tomadas quando se está na presença do sagrado36. O totem é a manifestação deste sentimento religioso, e este é a base no qual a sociedade se organiza e é organizada, pois todos os Fremen são sagrados como é Shai-Hulud e os vermes do deserto37.

Shai-Hulud não é uma entidade sobrenatural38, ou um espírito que vaga nas areias de Arrakis. Para Durkheim, há três classes de coisas sagradas que constituem a crença totêmica: o emblema, o animal e planta do emblema e os membros do grupo39. No caso das sociedades australianas que Durkheim tratou, era possível distinguir o totem da tribo, totem do clã, totens individuais, e, em alguns casos, o totem sexual. $\mathrm{O}$ mesmo não acontece com os Fremen. Há uma única tribo, dividida entre sietchs, sob o totem de Shai-Hulud, espalhadas no planeta. A manifestação de Shai-Hulud está nos vermes do deserto, nos Fremen, na Água da Vida, e também no que podemos chamar de uma pessoa-emblema, o messias Lisan al Gaib e/ou Mahdi. Poderia se levantar a questão que um sacerdote Fremen pudesse vir a ocupar a posição de profeta, ou de Messias. Todavia, para Weber, o profeta parte de uma revelação individual que é ampliada a partir de seu carisma40. O profeta não é o líder de uma nova escola filosófica, mas alguém que vai se inserir para produzir uma nova ordem ética41.

Lisan al Gaib é uma crença que teria sido levada para Arrakis pelas Bene Gesserit em uma missão de colonização religiosa sob o rótulo de Missionaria Protectiva. O mesmo pode ser dito de Mahdi, em torno de sua origem. Lisan al Gaib é a Voz do Mundo Externo42, um messias que viria para transformar Arrakis distribuindo água para todos. Mahdi também remete ao Messias, no mesmo sentido do paraíso na forma da água. Nesse conjunto de crenças, existe a noção de que o Messias viria de planeta

36DURKHEIM, The Elementary Forms of Religious Life, p. 36,38,39,40.

37Ibid., p. 128.

38Entendo sobrenatural no sentido da ideia de Deus dada por Spinoza - uma substância da qual há infinitos modos e infinitos atributos. Assim, não há nenhuma sobrenatureza em relação a essa natureza-substância. Ver: SPINOZA, Baruch, Ética, Belo Horizonte: Autêntica, 2010.

39DURKHEIM, The Elementary Forms of Religious Life, p. 140,143,144,145.

40WEBER, Economy and Society - An Outline of Interpretive Sociology. Volume 1 \& 2., p. 440.

41Ibid., p. 444.

42HERBERT, Dune.

REVISTA RELEgENS THRÉSKEIA - 20 I 8 - UfPR - UEPA 
externo e seria filho (ou filha) de uma Bene Gesserit.

Para Weber43, o que faz o profeta pode ser de tipo ético ou de tipo exemplar. O profeta ético estaria associado com a função da proclamação da vontade divina, sendo um instrumento desta. Já o profeta exemplar, como sugere sua tipologia, oferece a salvação para outrem a partir da mímica de seu comportamento. No caso de Paul, sua posição será ética, e a salvação de seus seguidores será atingida a partir do conflito - a Jihad.

A existência da missão Bene Gesserit para moldar a religião de Arrakis poderia significar que essa seria uma mera alucinação coletiva, servindo apenas como uma forma ideológica e um mecanismo de alienação e de dominação. Pensamos que tal acepção é equivocada por conta de dois fatores diferentes, mas relacionados. A religião, como desprendemos do pensamento de Durkheim, é uma forma de produção da unidade do grupo a partir de um conjunto de crenças e ritos que produz e estabelece a realidade. É essa vida social que origina o pensamento lógico, e é o framework da cognição. Uma ordem religiosa que tenha almejado manipular uma religião é, ela mesmo, uma religião que é reificada e celebrada por aquilo que teria sido seu produto. Essa circularidade do social é o que garante sua autoridade44.

O segundo é que, mesmo que alguns Fremen identifiquem Paul como o messias, essa posição sagrada não é dada de forma imediata. Ela precisa ser construída. As técnicas ascéticas ensinadas por sua mãe são uma ferramenta de inserção no sistema de representações coletivas, mas estão para além deles. Isso só pode ser compreendido a partir da análise dos rituais de sacralização, que vão moldando sua figura. E, para além disso, Paul também irá se inserir dentro do sistema de representação coletiva da sociedade imperial, tomando para si o trono e a posição de Kwisatz Haderach. Ou seja, se a Missionaria Protectiva foi capaz de manipular algo, não foi a sociedade Fremen (ou apenas ela), mas a própria ordem Bene Gesserit sob a ideia do Kwisatz Haderach.

Dentro do sistema de representações religiosas, supomos que existem duas classes: a sociedade macro-galáctica, de cunho feudal, dominada pelo Imperador, pelas Bene Gesserit, e pela Guilda Espacial e tencionada pelas Casas. O totem deste conjunto é o emblema do Imperador e não o imperador em si. Adjacente a esse, há o totem das Bene Gesserit, o Kwisatz Haderach. Para a classe macro-galáctica, o spice é sagrado. O

43WEBER, Economy and Society - An Outline of Interpretive Sociology. Volume 1 \& 2., p. 447,448. 44DURKHEIM, The Elementary Forms of Religious Life, p. 09,17,43,440.

REVISTA RELEgENS THRÉSKEIA - 2018 - UFPR - UEPA 
Kwisatz Haderach é sagrado apenas para as Bene Gesserit, e é um segredo da ordem, de modo que não pode ser considerado como uma representação coletiva. Esse cargo fica, portanto, com o emblema do Imperador.

A segunda classe é micro-desértica, de cunho tribal, dominada por uma sociedade sem Estado, na forma dos Fremen e estruturada a partir da religião de ShaiHulud. Este é um totem, e seu emblema é, em Dune45, Lisan al-Gaib, os vermes do deserto e os Fremen. Para a classe micro-desértica, a água é sagrada, mas também tudo aquilo que diz respeito ao animal totêmico46.

O rito do Gom Jabbar está inscrito dentro da classe macro-galáctica e é aplicado pela Reverend Mother Gaius Helen Mohiam, das Bene Gesserit. Além de uma liderança dentro da ordem, ela tem a função de Truth-Sayer do Imperador, um cargo de confiança da mais alta importância. Ou seja, trata-se de uma sacerdotisa que manipula o sagrado e carrega parte deste consigo.

O teste do Gom Jabbar é comum para as neófitas da Bene Gesserit, e sua aplicação em Paul era um caso especial. Jessica, que foi treinada na ordem e passou grande parte dos ensinamentos para seu filho, havia sido instruída para ter uma prole do sexo feminino. Esta seria direcionada para se casar com o herdeiro da casa Harkonnen, encerrando o feudo entre as duas famílias e o fruto dessa manipulação genética, que já durava milhares de anos, daria origem ao Kwisatz Haderach. Jessica cometeu, portanto, uma falta ritual, quando optou pelo filho. Para reintegrar essa falta, o Gom Jabbar foi utilizado para verificar se o herdeiro Atreides poderia vir a ser iniciado.

Jessica não sabia, na ocasião, mas posteriormente Paul toma consciência que ela era filha do Barão Harkonnen (algo que o Barão também desconhecia). Essa proximidade genética permitiu, ou tornou viável, a vinda de Paul antes daquele momento específico que era esperado pelas Bene Gesserit.

O Gom Jabbar verifica os termos da humanidade do indivíduo, a partir de testes. Aqui, há uma polarização importante, pois o que se testa, nos termos nativos, é a possibilidade de se tratar de um "humano" ou de um "animal”, mas a explicação nativa vai além disso. De acordo com Reverenda Madre Mohian, no passado, a humanidade foi escravizada pelas máquinas e foi necessário um grande confronto, conhecido como

\section{HERBERT, Dune.}

46Como tomamos por objeto apenas Dune (1965), deixamos esta questão fechada. Todavia, se o objeto de análise for expandido para os livros posteriores, quem irá assumir a função de totem, emblema do totem e animal totêmico é o Imperador Leto II, que se transforma em um híbrido de humano e sandworm. 
Butlerian Jihad, para recuperar o controle. Isso implicou na criação de um tabu, uma proibição expressa em um dos livros sagrados, a Bíblia Católica de Orange: "Não criarás uma máquina à semelhança da mente de um homem47”, que Mohian corrigiu como: "Não criarás uma máquina para imitar a mente humana48". Com o fim do conflito contra as máquinas, dois grupos surgiram: as Bene Gesserit e a Guilda Espacial, “a Guilda, ao que nos parece, ressalta a matemática quase pura49”, enquanto coube às Bene Gesserit, lidar com questões políticas, produzindo secretamente seu Kwisatz Haderach e separando a humanidade dos “animais"50.

A partir da teoria proposta por Mauss e Hubert51, podemos pensar no ritual do Gom Jabbar como dotado da seguinte estrutura: o sacrificante, que também é o objeto de sacrifício, é posto em uma sala onde Mohian que ocupa a posição de sacrificadora, encontra-se. Todos devem se retirar e, na parte de fora da porta, uma Bene Gesserit (que já tenha sido reconhecida como humana pelo ritual), impedirá a entrada de qualquer profano dentro daquele espaço. $\mathrm{O}$ espaço se torna sagrado durante o ritual, mas não precisa ter nenhuma outra característica especial. Internamente, o sacrificante é orientado a colocar a mão dentro de uma caixa, situação na qual sentirá um pequeno desconforto inicial. Essa entrada ritual pode se realizar com o sacrificante aceitando imediatamente a ordem, ou recusando. Se houver a recusa a Reverenda Mãe utilizará a Voz, resultando na obediência imediata da ordem dada. Na sequência, dois movimentos ocorrem.

O primeiro é que, a partir da mão, o sacrificante começa a experimentar alto grau de dor. Todavia, o segundo movimento, por parte da sacrificadora, impede qualquer tipo de movimento, pois uma agulha, com veneno letal, é posicionada no pescoço do sacrificante. Assim, caso a mão seja retirada da caixa sem a ordem, o sacrificante será eliminado imediatamente. O sacrificante será sacrificado. Durante o ritual, Paul murmura a oração Bene Gesserit, que foi ensinada por sua mãe, e que condensa o preceito básico da ideia do controle da mente sobre o corpo como aquilo que diferencia humanos e não-humanos: "Não terei medo. O medo mata a mente. O medo é a pequena morte que leva à aniquilação total. Enfrentarei meu medo. Permitirei que

47HERBERT, Duna, p. 29.

48Ibid.

49Ibid.

50Interessante que é justamente remover essa fronteira toda a jornada do Imperador Leto II.

51MAUSS; HUBERT, Sacrifice: Its Nature and Its Function.

REVISTA RELEgENS THRÉSKEIA - 2018 - UFPR - UEPA 
passe por cima e através de mim. E, quando tiver passado, voltarei o olho interior para ver seu rastro. Onde o medo não estiver mais, nada haverá. Somente eu restarei"52.

No caso de Paul, ele passa pelo ritual, permanecendo mais tempo do que qualquer outro homem que havia sido testado. A saída do ritual implica no retorno de Jessica para a sala, bem como uma discussão entre o sacrificante e o sacrificado. Assim, é explicado que o Kwisatz Haderach está ligado com uma droga e com a especiaria. Uma Bene Gesserit que passe pelo ritual, pode explorar as memórias de outras vidas passadas, mas, ainda assim, algo é proibido para elas: “mas há um lugar que nenhuma Proclamadora da Verdade enxerga. Ele nos repele e nos aterroriza. Dizem que um dia virá um homem que encontrará no dom da droga seu olho interior. Ele verá oque não podemos ver: o passado feminino e masculino53", sendo alguém definido como "aquele que é capaz de estar em muitos lugares ao mesmo54". Todavia, a Reverenda Madre alerta - outros homens já tentaram tal ritual superior, mas nenhum conseguiu: "Eles tentaram e fracassaram, todos eles?55", pergunta Paul Atreides, e é respondido: "Eles tentaram e morreram"56.

O Gom Jabbar, como um sacrifício de iniciação e ordenamento, carrega Paul para um primeiro conjunto de confirmações em torno do universo social e simbólico que ele participa. Corroborando com sua linhagem real, sua inserção simbólica permite o reconhecimento como humano e, no horizonte, a possibilidade de vir a se tornar o Kwisatz Haderach. O registro do animal e o tabu das máquinas que pensam, compõem juntos um tipo de sacralidade que é proibida para os humanos. Trata-se de uma outra forma religiosa que terá importância em outras narrativas do mesmo universo, mas que fogem da discussão deste texto.

Entre o Gom Jabbar e o próximo rito de iniciação em Arrakis, uma parte importante da histórica acontece. Os Atreides se mudam, estabelecem seu palácio, almejam selar uma aliança com os Fremen, mas são atacados pelos Harkonnen, estes que eram secretamente apoiados pelo Imperador. A maior parte dos soldados Atreides foi eliminada, e Duke Leto Atreides também foi morto.

Paul e Jessica conseguem fugir para o deserto e, em tal processo, vai se tornando

52HERBERT, Duna, p. 26.

53Ibid., p. 31.

54Ibid.

55Ibid.

56Ibid. 
cada vez mais evidente que o spice está afetando o herdeiro Atreides de modo cada vez maior. Sua mãe segue ensinando as nuances do controle e da maestria da Voz, bem como técnicas prana-bindu de controle corporal, mas a consciência de Paul vai muito além. É verdade que, antes do Gom Jabbar, Paul já experimentava sonhos intensos sobre Arrakis, mas após passar a residir no planeta onde o spice estava em tudo, a frequência, continuidade e percepção destes sonhos migraram para o estado desperto. Assim, quando a dupla encontra com os Fremen, Paul já havia passado por mudanças pessoais. a partir do spice, significativas. Todavia, estas não determinavam um futuro específico. No duelo com Jamis, que discutiremos em breve, constamentemente Paul reflete sobre os diferentes resultados que viu, desde uma vitória até sua morte.

Outro ponto, antes de seguir, é que os Fremen haviam se aproximado do Duke Leto, e traçado algumas possibilidades de aliança. Isso havia sido feito a partir da mediação de um representante do Império. O imperador que estava no trono e que havia se aliado com os Harkonnen era Shaddam Corrino IV. Seu pai, que ocupou o trono anteriormente, era Elrood Corrino IX. Durante seu governo, e com os Harkonnen controlando Arrakis, Elrood enviou o planetólogo Pardot Kynes para realizar expedições científicas lá. Esse planetólogo entrou em contacto com os Fremen e acabou se integrando em tal sociedade, na medida em que possuía um plano de viabilizar a produção de água em Arrakis. Ele não apenas ensinou aos Fremen diversas técnicas de captação e armazenamento de água, como também colocou-os dentro do sistema de controle do planeta.

Os Fremen percebem Pardot Kynes como: "ficou evidente para os Fremen que Kynes não era totalmente louco, só o suficiente para ser considerado um homem santo. Pertencia aos umma, a irmandade dos profetas. O espectro de Uliet foi promovido ao saudus, o trono dos juízes ancestrais57”. As bases lançadas por Pardot Kynes são continuadas por seu filho, Liet-Kynes, também planetólogo e secretamente Fremen. Durante o conflito entre os Atreides e Harkonnen, Liet foi indicado para servir como um juiz e verificar se a primeira transição entre casas estava ocorrendo conforme o imperador gostaria. Ele também seguiu o papel religioso de seu pai, sendo um líder entre os Fremen, e foi assassinado pelos Harkonnen durante a segunda mudança de 
regime. Nos termos da figura do profeta de Weber58, ambos os planetólogos estão mais próximos da posição de profetas exemplares, enquanto Paul seria um profeta de tipo ético. Chani, filha de Liet, estava entre os Fremen que encontram Jessica e Paul.

Este grupo de nativos, liderados por Stilgar, emboscou a dupla em uma caverna. De acordo com os costumes locais, a mulher seria morta e o jovem levado para servir a tribo. Todavia, quando o embate começou, Jessica rendeu, em poucos segundos, Stilgar, enquanto Paul derrubou outro Fremen e se ocultou. Treinada como Bene Gesserit, e passando esse ensinamento para Paul, ela dominava aquilo que os Fremen reconheciam como Doutrina dos sortilégios, uma técnica de combate extremamente eficaz. Rendido por ela, Stilgar propõe um acordo - ela ensinaria essa técnica de combate para os Fremen, e Stilgar garantia sua segurança e a de Paul no grupo. Assim, ela seria uma Sayyadina, uma ideia que ela reconhece como originada da Missionaria Protectiva, e que agora ela faria uso.

Essa técnica ascética dos sortilégios pode ser vista como aquilo que dota Jessica de uma sacralidade. Algo semelhante pode ser dito de sua origem Bene Gesserit, que também é reconhecida pelos Fremen. Ambos se combinam para permitir que ela venha a assumir essa posição de Sayyadina, mas a confirmação disto viria logo em seguida.

No dia seguinte, Jamis, o Fremen que foi derrubado por Paul durante a emboscada, invocou um rito de confirmação da posição de Jessica como a Sayyadiana. Tratava-se da lei de amtal, e significava que o nativo reclamava para si o direito de testar a posição dentro da lenda religiosa que estava sendo requisitada pela Bene Gesserit. O que implicava no combate com um representante dela, que não seria um Fremen, mas alguém externo ao grupo. Assim, coube a Paul travar confronto com Jamis. Além disso, Jamis invocou o direito ao silêncio, de modo que Jessica não poderia usar a Voz contra ele.

O espaço sagrado do ritual é dentro das cavernas, formado por um círculo das tropas Fremen. Os combatentes devem ingressar nele sem o trajestilador, e a arma utilizada para o ritual é a crysknife, que como vimos anteriormente, também é sagrada. Jamis utilizou uma faca pessoal, enquanto Paul emprestou uma de Chani. Uma vez que o combate começa, o duelo só se encerra com a morte de um dos combatentes. O que Jamis desconhecia é que Paul, além de ser treinado no regime ascético Bene Gesserit,

58WEBER, Economy and Society - An Outline of Interpretive Sociology. Volume $1 \& 2$. 
também foi ensinado pelos mestres de armas do seu pai, que eram considerados figuras formidáveis dentro do Império, como Gurney Halek e Duncan Idaho. Isso, junto com os efeitos que o spice vinham tendo sobre sua consciência, tornaram ele uma máquina de guerra. Jamis, que era um lutador experiente, é morto sem sequer conseguir encostar em Paul, e uma vez que isso aconteceu, o corpo logo foi recolhido para o grupo.

Um guerreiro Fremen era capaz de eliminar os soldados de elite do Imperador sem grandes dificuldades. Os quais, até então, eram considerados as forças mais bem treinadas de toda a galáxia. O fato de Paul conseguir eliminar um Fremen adulto sem dificuldade demonstra sua superioridade técnica de combate. Com Jamis morto, o título de Sayyadiana ficou garantido para Jessica, um ritual que conferiu tanto para ela, quanto para o sacrificante, Paul, a inserção dentro da tribo e sua sacralidade - travam-se agora de Fremen. Isso ganha maior dinâmica na forma do rito posterior a morte de Jamis, no qual Paul recebe um nome secreto, conhecido apenas pela tropa, sendo conferido por Stilgar: Usul, que significa a força que sustenta um pilar. Nome este que é aceito pela tropa.

Stilgar, na sequência, pede para Paul escolher um nome para ser conhecido por todos, que responde perguntando sobre o nome do pequeno rato que viu no deserto. $\mathrm{O}$ líder responde que se trata de Muad'Dib, e Paul toma para si, com um ajuste, pois não gostaria de abandonar sua origem Atreides, então Stilgar sugere que ele seja conhecido como Paul-Muad'Dib. Esse nome também é reconhecido pela tropa, e é essa que começa a murmurar as associações que já vinham sendo feitas. Stilgar explica que Muad'Dib é conhecido como o professor dos jovens, pois é esperto nas técnicas de vida no deserto e cria sua própria água. Ritualisticamente, Stilgar que também porta com si um grau de sacralidade pois é a figura de liderança do grupo, toca na testa de Paul com a mão, e depois retira e o abraça, murmurando seu nome secreto - Usul. O mesmo é repetido por toda a tropa.

No ritual de iniciação, o sacrificado foi Jamis, que passa por um rito funerário. Esse rito começa com um canto, "Ima trava okolo! I korenja okolo!”, que fala sobre cinzas e raízes. O corpo de Jamis é cremado, com o intuito de recuperar sua água. $\mathrm{O}$ corpo é profano, e pertence ao sujeito, mas a água para os Fremen é sagrada, e pertence ao grupo. A única "exceção" a essa regra é quando uma morte acontece em combate (não é uma exceção propriamente dita pois o indivíduo também pertence a tribo). 
No caso do combate entre Jamis e Paul, como foi travado sem a stillsuit, a água da transpiração do vencedor deve ser recuperada. Por isso, a água de Jamis agora pertenceria a Paul. O grupo, então, junta-se em torno de um vaso no qual a roupa de Jamis, e seus objetos pessoais são postos e vão ser redistribuídos entre o grupo. O primeiro a começar é Stilgar, que anunciou: "A arma de Jamis foi morta. Jamis foi chamado por Ele, por Shai-hulud, que estabeleceu as fases da lua que mínguam diariamente e, no fim, aparecem como gravetos tortos e secos. [...] Assim se passou com Jamis59”. Para os Fremen, o espírito de um sujeito não está no corpo, mas sim na água do corpo. E só abandona ele após o surgimento da próxima lua. O rito de distribuição dos objetos de Jamis celebra a relação que a tropa tinha com ele, começando por Stilgar que invoca sua amizade com o morto, para então separar um objeto para si e outro para a esposa de Jamis. Processo esse que é sempre reafirmado pela tropa. Na sequência do ritual, cada dos membros relembra que era amigo de Jamis, e conta um evento que foi significativo. São situações de dificuldade, onde a vida de um dependeu do outro, mostrando a importância daquele que havia morrido para os vivos. Paul tem uma certa hesitação em participar, mas sua mãe toma a frente, e diz que foi amiga de Jamis "quando o espírito dos espíritos dentro dele viu a necessidade da verdade, esse espírito se retirou e poupou meu filho"60.Isso abriu a possibilidade de Paul participar: "Paul sentiu seu eu diminuir ao se aproximar do centro do círculo. Era como se tivesse perdido um fragmento de si mesmo e o buscasse ali" 61 .

O sentimento de si que diminui é recaptado pelo grupo, na medida em que Paul começa a chorar, e conta que era amigo de Jamis, pois este ensinou que quando você mata alguém, há um preço por isso. Como a água é sagrada, o fato de Paul chorar implica em oferecer aos mortos aquilo que há de mais sagrado para o grupo, e todos vão tocar em seu rosto, depois reafirmando uns para os outros: "toque a face dele62", "senti o presente"63.Oferecer a água é uma dádiva. A cerimônia termina com o canto:

59HERBERT, Duna, p. 402,403.

60Ibid., p. 405.

61Ibid., p. 406.

62Ibid.

63Ibid. 
Chama por ti a lua cheia.../A Shai-hulud verás na areia; Lusco-fosco e noite magenta/ Tiveste morte tão sangrenta./ À lua redonda oramos calados.../ Com a sorte ditosa enfim premiados,/ O que procuramos será encontrado/ Na terra feroz onde o chão foi crestado. ${ }^{64}$

Encerrado o rito funerário em si, a substância sagrada que resta é a água de Jamis, que é contada e doada dentro de uma bolsa específica. A bolsa não fica sob a guarda de Paul, mas dos hidromestres, e com ele, ficam as hidrofichas, entendendo que estas são emblemas totêmicos que representam e remetem a uma sacralidade totêmica. Chani também comenta que ensinará, posteriormente, como carregar as hidrofichas sem fazer barulho, e Paul pede que ela os carregue. O que ele não percebe, mas a tropa considera como cômico, e Chani se assusta, é que solicitar para uma outra pessoa carregar suas hidrofichas significa que se está a cortejando. Todavia, Stilgar alivia a situação dizendo que Paul não sabia dos detalhes da cultura Fremen, e que ela poderia carregar as hidrofichas sem compromisso até que ele pudesse aprender.

Quando Paul chega até em Sietch Tabr, casa de Stilgar e da tropa, eles se encontram com a esposa de Jamis, Harah e seus dois filhos, Kaleff e Orlop. Em relação a Harah, Paul poderia escolher entre tomá-la como esposa, como Jamis havia feito quando matou o pai de Kaleff, Geoff, ou colocá-la sob seu serviço como uma empregada. Paul opta pelo segundo, uma vez que seu interesse estava em Chani antes mesmo de conhecê-la. Chani era uma presença constante nos sonhos de Paul desde Caladan. Kaleff e Orlop passam a ser considerados como seus filhos, e posteriormente serão treinados por ele e tornar-se-ão membros de sua guarda pessoal. Apesar de Harah duvidar, inicialmente, que Jamis teria sido derrotado por um jovem, os três aceitar-no-ão como o chefe legítimo da família.

Com os Harkonnen novamente no controle, o conflito com a população local aumenta e a posição de Sietch Tabr é ameaçada. Para evitar que a cidade secreta seja descoberta, é tomada a decisão de seguir para o deserto ao sul, para outra Sietch. Todavia, a Reverenda Madre da Sietch, a Bene Gesserit Rammalo, afirma que está velha demais e que não poderá realizar a viagem, chamada de hajra. Portanto a Sayyadina Jessica aceitou submeter-se ao ritual da Água da Vida, e caso sobrevivesse a ele, tornarse-ia a nova Reverenda Madre. Mas, para que o grupo não ficasse sem uma Sayyadina 
caso ela fracassasse, Chani, filha de Liet, foi consagrada como tal.

O processo de iniciação de Chani começou com o anúncio de que a sacrificante havia retornado de sua hajra e visto as águas (trata-se de um rito privado, possivelmente relacionado com algum totem sexual feminino). $\mathrm{O}$ enunciado foi confirmado pelo grupo e a Reverenda Madre pronunciou a consagração da filha de Liet como Sayyadiana, que a coletividade responde aceitando. Há um novo pronunciamento, em que a sacerdotisa reafirma sua posição como "cuja voz fala por muitas65" e:

Dou a ela os céus prateados, o deserto dourado e suas pedras reluzentes, os campos verdes que ainda virão. Isso dou à Sayydina Chani. E, para que não esqueça que serve a todos nós, a ela caberá as tarefas servis nesta Cerimônia da Semente. Seja feita a vontade de Shai-hulud. ${ }^{66}$

A próxima etapa do ritual pode ser vista como um outro ritual de iniciação, agora direcionado para Jessica. Aqui, há uma sequência importante de sacrifícios que antecederam, e que podem vir a ocorrer. Inicialmente, devemos considerar que será Chani, como Sayyadina, que ordenará, e que colocará a Água da Vida (sagrada mas impura para o consumo) na boca de Jessica. Essa substância é sagrada e, ao mesmo tempo, é um veneno. Cabe àquela que irá se tornar Reverenda Madre transformar e remover seu efeito nocivo. A substância só existe a partir do sacrifício de um criadorzinho na água, que expele, no momento de sua morte, essa água tóxica, captada por um hidromestre. A morte do Criadorzinho é um sacrifício do animal sagrado do grupo, sendo tratado com o maior grau de respeito possível (uma vez que, em si, matar um verme do deserto é um sacrilégio).

A primeira pergunta que Chani faz é sobre a presença da água, que é respondida pelos hidromestres: "Temos água, Sayyadina [...] mas dela não podemos beber"67. A segunda pergunta de Chani é sobre a semente, confirmada que sim pelo hidromestre (uma bolsa com especiaria). Ela entoa: “Abençoadas sejam a água e sua semente68”, e pergunta para Jessica se ela já sentiu o gosto da água sagrada, mas Chani se adianta e responde que não: "Não é possível que você tenha experimentado a água benta. Você vem de outro mundo e não teve esse privilégio69”. O que marca mais uma vez a

65Ibid., p. 452.

66Ibid.

67Ibid.

68Ibid., p. 453.

69Ibid. 
questão totêmica - a dádiva de devorar o totem sagrado é algo exclusivo da tribo. A próxima entoação remete ao sacrifício do verme do deserto: "Esta é a Água da Vida, a água que é maior que a água: Kan,a água que liberta a alma. Se você for uma Reverenda Madre, ela irá lhe abrir o universo. Que Shai-hulud seja o juiz70”.

Com a substância sagrada no corpo, Jessica experimenta uma jornada em sua consciência onde encontra a Reverenda Madre que a antecedeu e todas as outras que vieram antes. É o despertar da memória total do passado. Ao mesmo tempo, externamente, da sua boca começa a ser expelida a substância transformada (chamada de catalisador), e colhida por Chani para dentro da bolsa que carregava a Water of Life, purificando todo o conjunto. Esse é o aspecto positivo do contágio do sagrado. Todavia, Jessica cometeu uma falta ritual. Ela não avisou a Reverenda Madre que estava grávida, de modo que a filha que ainda estava em seu período de gestação inicial, foi desperta para a consciência também. O sagrado também é contagioso em um sentido negativo e as experiências estavam sendo entregues tanto para Jessica quanto para sua filha, que não estava pronta para isso. Quando nasceu, Alia Atreides tinha a memória de todas aquelas que a antecederam.

O ritual se encerra com Jessica tomando a palavra: "Conheci a Reverenda Madre Ramallo. [...] Ela se foi, mas continua aqui. Que sua memória seja celebrada no rito71". Assim, a Água da vida, agora purificada pela sacerdotisa, é distribuída por Chani e uma grande orgia se segue, na qual todos experimentam seus sentidos ampliados. Chani leva Paul para um outro espaço, consumando seu rito de união. No processo ritual, além do verme do deserto que foi sacrificado, a antiga Reverenda Madre também morre quando passa sua sacralidade para Jessica. Esses dois sacrifícios solidificam a posição da nova Reverenda Madre, apesar de produzirem uma falta ritual na forma de Aliah, que será considerada pelas Bene Gesserit como uma abominação, dotada de poderes maiores que a Reverenda Madre que havia aplicado o Gom Jabbar em Paul. Nos livros posteriores, Dune Messiah72 e Children of Dune73, essa falta ritual vai ganhar maiores proporções.

A narrativa prossegue e as forças Fremen lideradas por Paul sob o nome de Muad'Dib vão ganhando cada vez mais terreno contra os Harkonnen. Todavia, começa a se perceber uma certa instabilidade, pois, apesar de ser considerado como o messias, ele 
não passou pelo rito de iniciação da juventude - cavalgar um verme do deserto. A partir das técnicas que foram ensinadas por Stilgar e Chani, Paul consegue realizar a montaria e selar essa etapa de iniciação que estava faltando.

O próximo passo era resolver a demanda dos Fremen, na qual Muad'Dib deveria convocar Stilgar para o ritual de combate e assumir o controle da tribo. Todavia, tanto ele quanto sua mãe consideravam que a morte de Stilgar seria um ponto negativo e não teria nenhum valor para o cenário político que estava se consolidando. Assim, em um momento de efervescência antes do ataque à última cidade que ainda estava sob o controle Harkonnen, e que agora contava com a presença do Imperador e de toda a casa real, os Fremen começam a demandar o combate entre as lideranças

Nesse momento, e dotado de todo o carisma e sacralidade que vinha acumulando ao longo da narrativa, bem como usando de seu domínio ascético a partir da Voz, ele nega a possibilidade de entrar em um combate contra Stilgar pois nem este, nem qualquer outro, seria capaz de vencer um duelo contra ele. Sua autoridade não é mais Fremen, pois Stilgar se coloca sob seu comando gritando: "Longa vida ao duque Duke Paul-Muad'Dib!74", seguido do grupo que grita: "Ya hya chouhada! Muad'Dib! Muad'Dib! Muad'Dib! Ya hya chouhada!75”. Assim, com o anel ducal de seu pai em seu dedo (outra manifestação do emblema totêmico), a Jihad começa. Paul executa um rito de investidura vassálico com Stilgar, cruzando tanto o sistema de valores galáctico (na posição de duque) com o sistema de valores Fremen:

-Eu, Stilgar, recebo esta faca das mãos de meu duque - disse Stilgar, aceitando a arma branca e leitosa que Paul lhe oferecia.-Onde meu duque mandar, ali colocarei esta arma - disse Paul. Stilgar repetiu as palavras, falando com vagar e solenidade. Relembrando a origem do rito, Jéssica piscou para conter as lágrimas e sacudiu a cabeça. Sei qual é o motivo disto, ela pensou. Não deveria deixar que me afetasse. -Dedico esta arma à causa de meu duque e à morte de seus inimigos enquanto nosso sangue correr - disse Paul. Stilgar repetiu em seguida. - Beije a lâmina - ordenou Paul. Stilgar obedeceu; depois, à moda dos Fremen, beijou o braço com que Paul costumava empenhar a faca. Com o consentimento de Paul, ele embainhou a arma e ficou de pé. ${ }^{76}$

Paul, inscrito integralmente dentro do universo de representação religiosa Fremen, permanece insatisfeito com a incompletude de suas visões sobre o passado, 
presente e futuro. Para solucionar isso, decide tomar uma gota da Água da Vida e entra em um estado catatônico. Uma semana depois, Chani é chamada pela Reverenda Madre Jessica. Chani, na posição de Sayyadina explica ele entrou em um transe ritual e preparava-se para sua batalha final. Ela toca seus lábios com mais Água da Vida, e ele as transforma, realizando o ritual feito por Jessica, mas indo além dele, pois sua consciência não era apenas do passado, como do presente e do futuro. Confirmando-se e sendo confirmado por sua mãe, como o Kwisatz Haderach. É nesse momento que, finalmente, pode-se compreender que o Kwisatz Haderach é alguém capaz de ter a memória completa do passado, mas também do futuro.

As forças Fremen lideradas por Paul varrem as últimas resistências Harkonnen, bem como a maior parte da tropa de elite do Imperador. Este, preso em uma última sala em Arraken, cidade que outrora foi sede da casa Atreides, recebe a oferta do salvoconduto para fins de negociação. Neste momento, Paul propõe seu casamento com a filha mais velha do Imperador e a rendição imediata deste. O imperador recusa, mas Paul ameaça tanto as Bene Gesserit e a Spacing Guild. A partir da Water of Life catalisada, um grupo de seus soldados mais leais está posicionado para lançar essa substância em cima de uma massa de spice, o que irá resultar em uma explosão imediata, bem como na morte de todas as sandworms do planeta.

A Spacing Guild é a primeira em recuar sua posição de apoio ao Imperador, mas ainda há um último ritual que Paul deve passar para completar seu domínio religioso e político. Sua irmã Alia matou o Barão Harkonnen, mas seu herdeiro, Feyd-Rautha, estava entre a comitiva imperial. O imperador sugere que ambos lutem, com FeydRautha representando aquilo que chamamos de emblema imperial. Apesar de habilidoso, e de usar uma técnica para envenenar Paul, o Harkonnen não tem chance e é morto, com a adaga-crys sendo atravessada da parte de baixo da sua cabeça até seu cérebro.

Vitorioso, Paul ordena que o imperador seja afastado do cargo, e assume como regente. $\mathrm{O}$ imperador afirma que isso era uma quebra na promessa de salvo-conduto, mas Paul responde:

Sua pessoa está segura em minha presença - disse Paul. - Foi um Atreides quem prometeu. Muad'Dib, porém, condena você a seu planeta-prisão. Mas não tema, majestade. Aliviarei a aridez do lugar com todos os 
poderes a minha disposição. Irá se tornar um planeja ajardinado, cheio de amenidades. ${ }^{77}$

E, com isso, a Jihad de Mua 'Dib se espalha pela galáxia e o livro termina.

\section{Conclusão}

Nossa aposta inicial foi propor uma análise sociológica do funcionamento da religião em Duna. A partir das teorias de Durkheim, Mauss, Herbert e Weber, pudemos perceber uma complexidade presente na obra ficcional que entrelaça vários conceitos sociológicos importantes. Com Durkheim, percebemos como as formas elementares da vida alienígena são construídas a partir de uma oposição ontológica entre sagrado e profano. Para compreender como essas funcionam, as proposições de Mauss e Herbert nos foram fundamentais. A partir delas, tornou-se nítido como o personagem de Paul Atreides transita entre dois sistemas religiosos que apesar de relacionais eram distintos. Operando dentro desses rituais, Paul Atreides vai acumulando elementos de uma sacralidade que remetem a produção do profeta tal como retratada por Weber. Como duque e messias, Paul viabiliza seu acumulo de sacralidade a partir de um regime ascético que foi ensinado pela sua mãe. Por fim, o profeta messias consolida sua posição política como Imperador na medida que depõe seu antecessor e instaura na galáxia uma guerra santa, a Jihad, sob a autoridade de Mua’Dib.

\section{Referências}

BUDRYS, Algis. Review: Dune by Frank Herbert. Galaxy, v. 24, n. 4, p. 67-70, 1966.

DURKHEIM, Emile. The Elementary Forms of Religious Life. Trad. Joseph Ward Swain. London \& New York: George Allen \& Unwin, Ltd. \& The Macmillan Company, 1915.

HERBERT, Frank. Cease Fire. Astounding Science-Fiction, v. 60, n. 5, p. 51-68, 1958.

HERBERT, Frank. Chapterhouse: Dune. New York: New English Library, 1985.

HERBERT, Frank. Children of Dune. New York: Berkley Medallion Books, 1976.

HERBERT, Frank. Duna. Trad. Maria do Carmo Zanini. São Paulo: Aleph, 2017.

HERBERT, Frank. Dune. New York: Chilton Books, 1965.

HERBERT, Frank. Dune Messiah. New York: G. P. Putnam's Sons, 1969.

HERBERT, Frank. Dune World (Part 1 of 3). Analog Science Fiction - Science Fact, v. LXXII, n. 4, p. 17-48, 1963. 
HERBERT, Frank. Dune World (Part 2 of 3). Analog Science Fiction - Science Fact, v. LXXII, n. 5, p. 48-85, 1964.

HERBERT, Frank. Dune World (Part 3 of 3). Analog Science Fiction - Science Fact, v. LXXII, n. 6, p. 40-71, 1964.

HERBERT, Frank. God Emperor of Dune. New York: New English Library, 1981.

HERBERT, Frank. Heretics of Dune. New York: New English Library, 1984.

HERBERT, Frank. Looking for Something? Startling Stories, v. 25, n. 3, p. 124-140, 1952.

HERBERT, Frank. You Take the High Road. Astounding Science-Fiction, v. 61, n. 3, p. 97-108, 1958.

MAUSS, Marcel; HUBERT, Henri. Sacrifice: Its Nature and Its Function. Trad. W. D. Hall. Chicago: University of Chicago Press, 1964.

MERRIL, Judith. Review: Dune by Frank Herbert. The Magazine of Fantasy and Science Fiction, v. 30, n. 3, p. 51, 1966.

MILLER, P. Schuyler. Review: Dune by Frank Herbert. Analog Science Fiction Science Fact, v. LXXVII, n. 2, p. 140, 1966.

SPINOZA, Baruch. Ética. Trad. Tomaz Tadeu. Belo Horizonte: Autêntica, 2010.

WEBER, Max. Economy and Society - An Outline of Interpretive Sociology. Volume 1 \& 2. Trad. Ephraim Fischoff, Hans Gerth, A. M. Henderson, et al. Berkeley, Los Angeles, London: University of California Press, 1968. 